Review

\title{
Improving rational drug use in Africa: the example of Sudan
}

A.I. Awad, ${ }^{1}$ D.E. Ball ${ }^{1}$ and I.B. Eltayeb ${ }^{2}$

$$
\begin{aligned}
& \text { تحسين الاستخدام الرشيد لالأدوية في أفريقيا - مثال من السودان }
\end{aligned}
$$

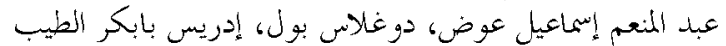

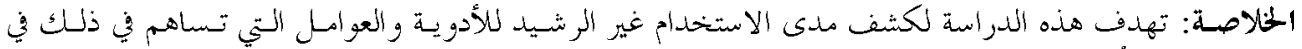

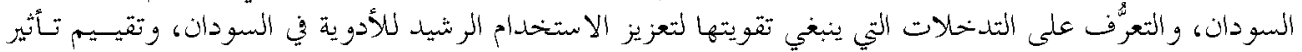

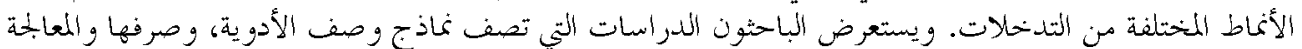

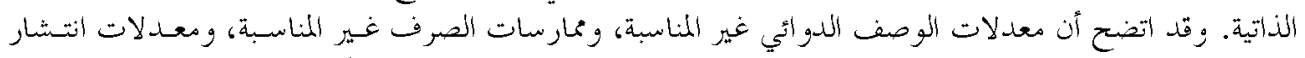

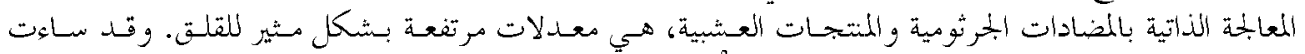

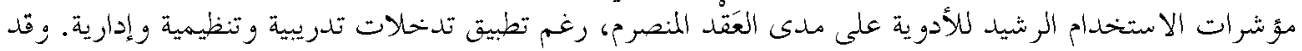

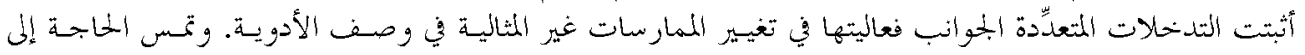

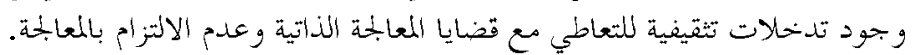

ABSTRACT The aim of this review is to determine the extent of irrational drug use and contributing factors in Sudan and to identify the interventions that need to be strengthened to promote the rational use of drugs in the country and to evaluate the impact of different types of intervention. We present an overview of studies describing patterns of drug prescribing, dispensing and self-medication. Rates for inappropriate prescribing and dispensing practices and prevalence of self-medication with antimicrobials and herbal products were alarmingly high. Indicators of rational drug use have worsened over the past decade despite the implementation of managerial, regulatory and training interventions. Multifaceted interventions have proved effective in changing suboptimal prescribing practices. Educational interventions are needed to address self-medication and adherence.

Pour une meilleure utilisation rationnelle des médicaments en Afrique : I'exemple du Soudan RÉSUMÉ Cette synthèse se propose de déterminer l'ampleur de l'utilisation irrationnelle des médicaments au Soudan et les facteurs qui y contribuent, d'identifier les interventions qu'il convient de renforcer pour promouvoir l'utilisation rationnelle des médicaments dans ce pays et d'évaluer l'impact des divers types d'intervention. Nous donnons ici une vue d'ensemble des études décrivant les différents mécanismes présidant à la prescription et la dispensation des médicaments et à l'automédication. La fréquence des actes de prescription et de délivrance non conformes et la prévalence de l'automédication en matière d'antibiothérapie et de phytothérapie atteignent un niveau particulièrement alarmant. En dépit de la mise en oeuvre d'interventions dans les domaines managérial, réglementaire et formatif, les indicateurs de l'utilisation rationnelle des médicaments trahissent une aggravation au cours de la dernière décennie. Les interventions multiformes s'avèrent efficaces pour une modification des pratiques prescriptives suboptimales. Automédication et observance sont autant d'aspects nécessitant la mise en place d'interventions éducatives.

${ }^{1}$ Department of Pharmacy Practice, Faculty of Pharmacy, Kuwait University, Kuwait (Correspondence to A.I. Awad: amoneim@hsc.edu.kw).

${ }^{2}$ Department of Pharmacology, Faculty of Pharmacy, University of Khartoum, Khartoum, Sudan.

Received: 17/07/05; accepted: 15/11/05 


\section{Introduction}

While it is recognised that approximately one third of the world's population has no access to essential medicines, the appropriate prescription and use of medicinesrational drug use (RDU) - is a crucial part of national health policy, particularly since more than $50 \%$ of national and $60 \%-80 \%$ of individual health care spending in developing countries goes towards medicines [1]. RDU has been defined as when "patients receive medications appropriate to their clinical needs, in doses that meet their individual requirements for an adequate period of time and at lowest cost to them and their community" [2].

Common examples of irrational drug use include use of antimicrobials for viral infections and over-prescribing of injections. Such practices result in waste of resources, inappropriate patient demand, antimicrobial resistance and increased drugrelated morbidity and mortality [3].

Sudan, capital city Khartoum, is the largest country in Africa, with an estimated (2004) population of over 33 million [4]. Crude oil exports have led to an increase in per capita gross domestic product (GDP) since 1999 (purchasing power parity US\$ 1900 in 2004). However, chronic instability in southern Sudan and Darfur, adverse weather, and weak world commodity prices have contributed to continuing poverty and ill health.

The public health-care system is based on primary health care, with village primary health care units feeding into urban rural hospitals and health centres, while morespecialized hospitals provide tertiary level care. Health services provision was free prior to the 1990s, but health facilities now operate on a fee-for-service basis resulting in the majority of the population not being able to afford basic health services. Sudan has a child mortality rate of 64 per 1000 and life expectancy of 56 years [4]. Total expenditure on health is about $3.5 \%$ of GDP, and per capita total health expenditure US\$ 14 (2001 estimate). There are approximately 18 doctors, 2 pharmacists and 51 nurses per 100000 population.

With this background, Sudan, along with many African countries, is facing difficulties in providing access to essential medicines and ensuring that these medicines are used appropriately. In this article, activities relating to measuring and improving the rational use of drugs in Sudan are described and reviewed. Examination of these experiences will be used to provide insight into the extent of irrational drug use in the country and the factors contributing to this problem so as to provide recommendations on strengthening the promotion of the rational use of drugs in the country in the future.

To provide a complete picture and illustrate the scale of the problem, purely descriptive studies have been included as well as those which contain an intervention. Where an intervention is present, the study is described in more detail so as allow interpretation of the outcome, the factors leading to success or failure and the resources (both human and financial) required to implement the intervention. It is hoped that this may also provide opportunity for other countries on the continent to learn from these practical experiences.

\section{Sources of information}

Studies for this paper were identified by searching Medline, the International Network for the Rational Use of Drugs bibliographic database (www.inrud.org) and the World Health Organization (WHO) website for articles on Sudan related to RDU. In addition, authors of published works and Federal Ministry of Health officials were approached to identify other local RDU activities and published studies. All identified reports were included in this review. 


\section{Drug use indicator studies}

Baseline data with regard to RDU in Sudan [5] also served as part of field testing for the WHO drug use indicators [6,7]. An initial survey (1991) found an average of 1.4 drugs per encounter (prescription), with $63 \%$ of medicines prescribed by generic name, $63 \%$ of encounters with an antibiotic and $36 \%$ with an injection (Table 1). Three subsequent surveys provided comparative data. A 1996 survey [8] found that RDU indicators had worsened except for a decrease in the prescription of injections: while a smaller proportion of drugs were prescribed by generic name, almost all prescribed drugs were on the Sudan Essential Medicines List (EML) and most were dispensed and adequately labelled (Table 1). A later survey of health facilities participating in a revolving drug fund reported a greater average number of drugs per prescription and a smaller proportion of generic drugs and antibiotics prescribed [9]. Outpatient prescribing at hospital level [10] was no "worse" than that measured at primary level with an average number of drugs of 1.9. Ge-

Table 1 Summary of surveys investigating medicine use in Sudan using World Health Organization drug use indicators [7]

\begin{tabular}{|c|c|c|c|c|c|}
\hline \multirow[t]{2}{*}{ Parameter } & \multicolumn{5}{|c|}{ Survey site [source] } \\
\hline & $\begin{array}{c}\text { Nile } \\
\text { Province } \\
\text { [5] }\end{array}$ & $\begin{array}{l}\text { Khartoum } \\
\text { State }[8]\end{array}$ & $\begin{array}{l}\text { Khartoum } \\
\text { State }[9]\end{array}$ & $\begin{array}{l}\text { Khartoum } \\
\text { State [10] }\end{array}$ & $\begin{array}{c}\text { Developing } \\
\text { countries } \\
{[6,7]}\end{array}$ \\
\hline Date of survey & 1991 & 1996 & 1998 & 2004 & 1990-1994 \\
\hline Type of facility (no.) & $\begin{array}{c}\text { Primary } \\
\text { health } \\
\text { centre (37) }\end{array}$ & $\begin{array}{c}\text { Primary } \\
\text { health } \\
\text { centre }(20)\end{array}$ & $\begin{array}{c}\text { Hospital } \\
\text { (12); health } \\
\text { centre (75) }\end{array}$ & $\begin{array}{c}\text { Teaching } \\
\text { hospital (2) }\end{array}$ & $\begin{array}{c}\text { Primary } \\
\text { health } \\
\text { centre (12) }\end{array}$ \\
\hline Encounters per facility & 30 & 30 & $>100$ & 100 & Varied \\
\hline \multicolumn{6}{|l|}{ Prescribing indicator } \\
\hline $\begin{array}{l}\text { Average no. drugs/encounter } \\
\text { Drugs prescribed by generic }\end{array}$ & 1.4 & 1.9 & 2.1 & 1.9 & 2.4 \\
\hline name ${ }^{a}$ & 63 & 48 & 41 & 43 & 52 \\
\hline Antibiotic prescribed ${ }^{a}$ & 63 & 73 & 59 & 65 & 43 \\
\hline Injection prescribed ${ }^{a}$ & 36 & 22 & 29 & 10.5 & 25 \\
\hline Prescribing from EML ${ }^{a}$ & - & 98 & 99 & - & - \\
\hline Antimalarial prescribed ${ }^{a}$ & - & - & 33 & - & - \\
\hline \multicolumn{6}{|l|}{ Patient care indicator } \\
\hline Average consultation time (minutes) & - & 1.4 & - & 4.7 & 4.2 \\
\hline Average dispensing time (seconds) & - & 33 & - & 46 & 79 \\
\hline Prescribed drugs dispensed (\%) & - & 90 & 100 & 85 & 87 \\
\hline Drugs adequately labelled (\%) & - & 81 & 100 & 38 & - \\
\hline Dose understood by patient (\%) & - & 90 & - & 37 & 67 \\
\hline \multicolumn{6}{|l|}{ Facility indicator } \\
\hline Availability of EML (\%) & - & 100 & 100 & - & - \\
\hline Availability of key drugs (\%) & - & 93 & 100 & - & 75 \\
\hline
\end{tabular}

\footnotetext{
a\% of encounters

$E M L=$ essential medicines list.

$-=$ data not available.
} 
neric prescribing was low, but consultation times were markedly longer. Labelling was poor and patient knowledge of the drugs was low. However, different standards for what was expected of the patients were used compared to earlier studies when patients were only asked whether they knew the dose they were supposed to take.

These studies show the value of druguse indicator studies in providing a snapshot of prescribing and patient care issues. Their value has, however, been undermined by the lack of a systematic mechanism, resulting in studies using varying mixes of health centres and standards. Additionally, since the WHO indicators provide insight into the drug use process but are not designed to address whether drugs are being used appropriately for specific indications [7], further studies are required to determine the scale and nature of any potential problems.

\section{Adherence to clinical guidelines}

A retrospective study was conducted at 20 health centres in Khartoum State to examine the appropriateness of prescribing of antibiotics, antimalarials and giardiasis/ amoebiasis therapy relative to the Sudan National Formulary (SNF) [11]. The findings were disappointing with only one fifth of prescriptions for giardiasis/amoebiasis and one quarter of prescriptions for antibiotics and chloroquine in children following the national treatment guidelines (Table 2). Antibiotic prescribing in adults was little better with about $42 \%$ of patients receiving the drug as recommended. Many of the prescribing errors for antibiotics were related to reduced durations of treatment and incorrect dosing intervals for amoxicillin and erythromycin [12]. Focus group discussions with prescribers and dispensers identified lack of knowledge of the age-related doses compounded by an absence of the SNF at
Table 2 Prevalence of inappropriate prescribing reported in various studies in Sudan

\begin{tabular}{lc}
\hline Disease/drug class & $\begin{array}{c}\text { Inappropriate } \\
\text { prescribing }^{\mathrm{a}} \text { (\%) }\end{array}$ \\
\hline Giardiasis/amoebiasis $^{\mathrm{b}}$ & 82 \\
Antibiotics for adults $^{\mathrm{b}}$ & 58 \\
Antibiotics for children $^{\mathrm{b}}$ & 77 \\
Chloroquine for children $^{\mathrm{b}}$ & 76 \\
Antimalarials $^{\mathrm{c}}$ & 45 \\
\hline
\end{tabular}

alnappropriate prescribing defined as prescribing at dose or dosing frequency or duration other than that recommended in the clinical guidelines of the Sudan National Formulary.

${ }^{b}$ Source $[11,12]$

'Source [13].

most of the centres (92\%) although three quarters of participants reported having attended an RDU training course and possessing the SNF.

Poor prescribing of antimalarials, mostly chloroquine and quinine, was also seen in a prospective survey of 400 prescriptions presented to a public retail pharmacy in Gezira State [13]. Injections were commonly prescribed ( $45 \%$, mostly intramuscular) in spite of the outpatient nature of the population, and recommended dosage regimens were followed in only $55 \%$ of cases. Chloroquine was commonly prescribed for a longer duration than necessary.

Incorrect or incomplete prescriptions were also identified as a problem in retrospective surveys of acute and chronic asthma cases at Shaab teaching hospital in Khartoum State [14]: it was found that while most prescriptions provided the dosage form and directions for use, other pertinent information, e.g. quantity to be dispensed or prescriber's signature, was often missing. In the prescribing for the management of acute asthma, $32 \%$ of admission sheets had no record of recommended routine investigations, but the retrospective nature 
of the study precluded determining whether these investigations had actually been carried out. There was wide variation in the dosing of nebulised salbutamol and hydrocortisone with no patients receiving the regimen according to recommended clinical guidelines. It was, however, acknowledged that the national guidelines were not current and this, in addition to the varied case load, could have led physicians to follow alternative approaches to management.

Another study examined prescription errors at 3 paediatric hospitals in Khartoum State [15], 840 prescriptions were examined and $80 \%$ of them had $\geq$ "error"; the most common dosing error $(81 \%)$ was the omission of the strength, the route of administration was unclear in $14 \%$ and many prescriptions also had data such as the prescriber's signature, age of the child and date of prescribing often missing.

Up-to-date clinical guidelines are a useful tool for the prescriber as well as the policy-maker. These studies exhibited significant deviations from the recommended management of common diseases and problems in prescription writing which could contribute to medication-related problems. The combination of qualitative and quantitative methodologies allowed for some of the reasons for the behaviour to be understood. This is essential for designing effective interventions by local or national managers to address these issues.

\section{Interventions to change prescribing}

There is little point in studying medicine use if this is not translated into action to change suboptimal practices. Ideally, those with the greatest effect (clinically or costwise) should be targeted. Two studies in
Sudan have investigated methods of actually changing prescribing behaviour for antibiotics in general. The first study built on the evidence of inappropriate antibiotic prescribing at health centres in Khartoum State $[11,12]$. Twenty health centres were randomly assigned into 4 groups to receive either no intervention; audit and feedback; audit and feedback plus seminars; or audit and feedback plus academic detailing. This study confirmed the observations of inappropriate prescribing and showed that it could be improved through audit and feedback combined with either seminars or academic detailing: at 3 months, the number of antibiotics prescribed had fallen by $49 \%$ and $53 \%$ respectively and the number of prescriptions with inappropriate doses or durations decreased by $58 \%$ and $74 \%$ respectively (all $P<0.001$ ). Audit and feedback alone produced a decrease of about $20 \%$ in both measures but this was not statistically significant [16].

A similar study was performed to evaluate the effect of multifaceted interventions on prescribing patterns for sexually transmitted infections in the White Nile State. The study involved 20 health centres randomly assigned to 4 groups: no intervention; audit and feedback; audit and feedback plus seminars plus practice guidelines; and audit and feedback plus academic detailing plus practice guidelines. Audit and feedback together with either seminars or academic detailing combined with practice guidelines reduced the number of inappropriate prescriptions by $43 \%$ and $50 \%$, respectively (all $P<0.001$ ). Audit and feedback alone reduced inappropriate prescriptions by $16 \%$ but this was not statistically significant [17].

It has been shown that multifaceted interventions are more likely to succeed $[3,18]$ but these are more resource intensive. These investigations showed that inap- 
propriate prescribing can be changed with multifaceted interventions and indicated that, in the long term, supervisory visits combined with audit and feedback could have a similar effect to more resourceintensive academic detailing.

\section{Self-medication}

While prescribing habits are an important part of the quality use of medicines, the patient's own practices in using medicines are also important [19]. A number of community-based studies have been performed in Sudan examining patient selfmedication with antibiotics and antimalarials in Khartoum State.

A survey of 1750 adults from urban areas in Khartoum State found that $73.9 \%$ of the study population had used antibiotics or antimalarials without a prescription within 1 month prior to the study. Self-medication with either antibiotics or antimalarials was found to be significantly associated with the age group $<40$ years, low and intermediate income earners, female sex and high level of education; $68.8 \%$ of the respondents who had self-medicated obtained the drugs directly from private pharmacies. Antibiotics were commonly being used for cough and the common cold or genitourinary symptoms, and $39 \%$ of those who self-prescribed with antibiotics/antimalarials reported incorrect doses and/or inappropriate duration of use of the medication [20].

These results were mirrored in a survey of 200 university students: when selfmedicating with antibiotics, most students $(59 \%)$ used the drug for less than 5 days. Laboratory investigations were an aid to diagnosis for $60 \%$ of respondents, with most of the remainder relying on past experience. Over $90 \%$ of medicines had been obtained through community pharmacies without prescriptions [21].
In a survey of 1000 households from Khartoum State, $81.8 \%$ of the study population had used medicines, including herbal remedies, without a medical consultation within 2 months prior to the study period [22]. Self-medication with any medicine or herbal remedy was found to be significantly less common with the middle-aged (40-59 years) and the elderly and those with a low level of education. It was most associated with female sex and with low and middle income earners. The main source of medicines was private pharmacies $(80 \%)$, which were seen as cheaper than other primary health care sources. Antibiotics were the most common medicine used for self-medication $(36.3 \%)$ and they were being used for cough and the common cold.

A separate survey of 469 households from Gezira state found that virtually all had at least 1 pharmaceutical stored at home, with around half of all households reporting practising self-medication, reuse of stored medicines and exchange of drugs between family members, and $71 \%$ reported poor compliance [23].

Elsewhere, use and proper preparation of oral rehydration solution by mothers was found to be lacking and associated with harmful practices for management of diarrhoea in children [24].

Such inappropriate use of drugs such as antibiotics and antimalarials is likely to lead to increased resistance to the medication and could have significant public health implications in the future $[25,26]$. Selfmedication plays a large part of people's health behaviour and the public also needs education in the appropriate use of medicines. This should take into account cultural beliefs and the influence of social factors. The WHO has published resource materials for investigating community medicines use [19] and educating the community on RDU [27]. 


\section{Policy interventions}

The above studies were carried out against the background of the activities to address access to and rational use of drugs by the Federal Ministry of Health and partner organizations, e.g. WHO. Sudan was an early adherent to the essential drugs concept. A National Drug Policy was formulated and adopted in 1981 which formed the foundation for the Sudan EML in 1982 (updated 1985, 1987, 1995, 2001). The SNF, which includes national treatment guidelines, was first produced in 1991 (currently being updated) and health insurance was introduced for civil servants in 1995 .

More recent activities have built upon these foundations. These have included training workshops on RDU, drug supply management, the Sudan EML and SNF, and other areas relevant to the procurement and distribution of quality pharmaceuticals for all levels of health workers, particularly over the past 5 years. Regulatory mechanisms on the registration of medicines, licensing of health professionals and inspections of pharmacies have been strengthened, and a medicines information centre and RDU unit have been established in the Federal Ministry of Health. Recently, the deans of medicine, pharmacy, dentistry and nursing faculties from all universities in Sudan have been introduced to the importance of RDU to encourage the introduction of this concept into undergraduate curricula.

\section{Discussion and recommendations}

In spite of increased availability of medicines through early application of the essential medicines concept, the advantages of RDU training workshops and clinical guidelines have not been realized in Sudan.
It is difficult to identify all the causes of this from a literature review, but certain reasons are apparent: while an EML and clinical guidelines have been developed and distributed, they are not being applied by health workers on the ground. Common reasons for this are a process which is nonparticipatory and/or not widely consultative, which results in a product over which most of the target group do not feel a sense of ownership. In addition, a process of implementation needs to be harmonized with that of distributing the EML or clinical guidelines to convert health workers to the concept and use of the new material, changing their habitual practices [28-32].

National EMLs and treatment guidelines need to be regularly updated to maintain authority and, while the Sudan EML has been updated every 5-6 years, a second edition of the SNF has not been issued since the original in 1991. This also makes interpretation of RDU studies difficult since prescribers will abandon guidelines they see as out-of-date.

Training of health workers has been undertaken by the government, but this does not appear to have been successful. Workshops for health workers are popular strategies in African countries, but their effectiveness in changing behaviour is seldom assessed. Problem-based learning has been shown to improve prescribing skills of medical students [33], but changing ingrained habits is more difficult. Multifaceted interventions at a local or regional level were found to be effective in this review, but individual factors and causes need to be taken into account and current in-service training strategies should be revised and evaluated. Unbiased medicine information resources also need to be made available to counter pharmaceutical industry marketing, and professional societies can address the knowledge base of their members through 
continuing professional development programmes, especially in addressing their role in self-medication.

Resources to implement such measures are, however, often limited in developing countries; rural health centres are often excluded and appropriate implementation of such strategies is pivotal if they are to be successful in supporting changes to medicines use [32,34]. Academic detailing has been shown to be successful, but would not appear to be cost-effective given that group seminars (as part of a composite intervention) had a similar effect, and supervision by suitably trained persons combined with audit and feedback mechanisms can have significant benefits $[3,35]$.

Implementation of pharmaceutical care in community pharmacies could help alleviate the problem of inappropriate selfmedication although care must be taken to develop a suitable model given the environment in which they operate. Community pharmacists can play an active role in the provision of primary health care, health promotion, and protecting and improving public health [36]. They can also monitor the safety of over-the-counter medicines and herbal remedies. Sudanese pharmacists may also need to improve their clinical knowledge and skills and must be willing to be responsible for the patient's drug therapy and develop close working relationships with other health care professionals.

The most obvious missing ingredient in this overview is some form of coordination between field researchers and policymakers, something which is necessary for translating research into policy. This could be based wholly within a government depart- ment as was the case in Zimbabwe [37] or could be a symbiotic collaboration between local universities and the Federal Ministry of Health. The formation of an RDU unit in the Sudanese Federal Ministry of Health is welcomed in this regard. Since policymakers are often driven by "the bottom line", adding pharmacoeconomic analysis to RDU studies could be useful to assess the costeffectiveness of RDU interventions.

\section{Conclusion}

In conclusion, much has been learned from past successes and failures in measuring and changing medicine prescribing and use in Sudan and other countries. It is recommended that training and implementation strategies be combined with the distribution of national treatment guidelines in the future. Such strategies, as well as interventions to address inadequacies in prescribing or medication use, should be multifaceted.

For optimal effect, programmes to address rational drug use should involve academics and governmental and partner organizations working in concert to address the continued problems of irrational drug use in Sudan and elsewhere on the African continent.

\section{Acknowledgements}

We would like to thank pharmacists Sara Tigani and Ghada Shouna from the Department of Rational Drug Use, Federal Ministry of Health for their cooperation in providing information for this article.

\section{References}

1. WHO medicines strategy: framework for action in essential drugs and medicines policy 2000-2003. Geneva, World Health Organization, 2000 (WHO/EDM/2000.1).
2. The rational use of drugs: report of the conference of experts. Geneva, World Health Organization, 1985. 
3. Promoting rational use of medicines: core components. WHO policy perspectives on medicines. Geneva, World Health Organization, 2002 (WHO/EDM/2002.3).

4. Human development report, 2004. New York, United Nations Development Programme, 2004.

5. Bannenberg WJ et al. Evaluation of the Nile province essential drugs project. Geneva, World Health Organization, 1991 (WHO/DAP/91.10).

6. Hogerzeil HV et al. Field tests for rational drug use in twelve developing countries. Lancet, 1993, 342(8884):1408-10.

7. How to investigate drug use in health facilities: selected drug use indicators. Geneva, World Health Organization, 1993 (WHO/DAP/93.1).

8. Abdelmoneim IA, El-Tayeb IB, Omer ZB. Investigation of drug use in health centers in Khartoum State. Sudan medical journal, 1999, 37:21-6.

9. Ali GK. Management of revolving drug fund: experience of Khartoum State - Sudan [thesis]. Bradford, UK, University of Bradford, 2000.

10. Awad Al, Himad H. Drug use practices in teaching hospitals of Khartoum state, Sudan. European journal of clinical pharmacology, 2006, 62(12):1087-93.

11. Eltayeb IB, Awad AI. Prescribing patterns in health centres in Khartoum State. Sudan medical journal, 1996, 34:63-9.

12. Awad AI, Eltayeb IB. Antibiotics use: patients in health care centres in Khartoum State. Sudan medical journal, 2001, 39:29-32.

13. Yousif MA, Adeel AA. Antimalarials prescribing patterns in Gezira State: precepts and practices. Eastern Mediterranean health journal, 2000, 6(5/6):939-47.

14. Abdelhamid K. Implementation and evaluation of pharmaceutical care service in
Sudanese asthmatic patients [thesis]. Khartoum, University of Khartoum, 2004.

15. Shadia AS. Prescription errors in Khartoum paediatric hospitals. Khartoum pharmacy journal, 2003,13:16-7.

16. Awad Al, Eltayeb IB, Baraka OZ. Changing antibiotic prescribing practices in health centers in Sudan. European journal of clinical pharmacology, 2006, 62(2):13542.

17. Eltayeb IB et al. Changing the prescribing patterns of sexually transmitted infections in the White Nile Region of Sudan. Sexually transmitted infections, 2005, 81(5):426-7.

18. Grimshaw JM et al. Effectiveness and efficiency of guideline dissemination and implementation strategies. Health technology assessment, 2004, 8(6)(iii-iv):172.

19. Hardon A, Hodgkin C, Fresle D. How to investigate the use of medicines by consumers. Geneva, World Health Organization, 2004 (WHO/EDM/PAR/2004.2).

20. Awad Al et al. Self medication with antibiotics and antimalarials in the community of Khartoum State, Sudan. Journal of pharmacy and pharmaceutical sciences, 2005, 8(2):326-31.

21. Awad Al, Ahmed A, Matowe L. Self-medication with antibiotics and antimalarials among university students in Sudan. Basic and clinical pharmacology \& toxicology, Abstract Book 2005, 97(Suppl. 1), Abstract No 283. Proceedings of the 7th Congress of the European Association for Clinical Pharmacology and Therapeutics, June25-29 2005, Poznan, Poland. Copenhagen, Nordic Pharmacological Society, 2005.

22. Awad AI, Eltayeb IB, Capps P. Selfmedication practices in Khartoum state, Sudan. European journal of clinical pharmacology, 2006, 62(4):317-24. 
23. Yousif MA. In-home drug storage and utilization habits: a Sudanese study. Eastern Mediterranean Health Journal, 2002, 8(2/3):422-31.

24. Ahmed IS et al. Knowledge, attitudes and practices of mothers regarding diarrhoea among children in a Sudanese rural community. East African medical journal, 1994, 71:716-9.

25. Okeke IN, Lamikanra A, Edelman R. Socioeconomic and behavioral factors leading to acquired bacterial resistance to antibiotics in developing countries. Emerging infectious diseases, 1999, 5(1):18-27.

26. White NJ et al. Averting a malaria disaster. Lancet, 1999, 353(9168):1965-7.

27. Fresle D. Rational drug use: consumer education and information. Geneva, World Health Organization, 1996 (DAP/

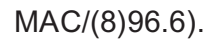

28. Graaff PJ, Forshaw CJ. Developing standard treatment guidelines in Malawi. Essential drugs monitor, 1995, 19:12-4.

29. Fourteen years with an essential drugs list: Zimbabwe's experience. Essential drugs monitor, 1995, 19:17-8.

30. Laing R. Essential drugs programmes in Africa. Africa health, 1991, 14(1):32-3.

31. Laing RO, Hogerzeil HV, Ross-Degnan D. Ten recommendations to improve use of medicines in developing countries. Health policy planning, 2001, 16(1):13-20.

32. Bero LA et al. Closing the gap between research and practice: an overview of systematic reviews of interventions to promote the implementation of research findings. British medical journal, 1998, 317(7156):465-8.

33. De Vries TP et al. Impact of a short course in pharmacotherapy for undergraduate medical students. Lancet, 1995, 346(8988):1454-7.

34. Davis DA et al. Changing physician performance. A systematic review of the effect of continuing medical education strategies. Journal of the American Medical Association, 1995, 274(9):700-5.

35. Trap B et al. The impact of supervision on stock management and adherence to treatment guidelines: a randomized controlled trial. Health policy and planning, 2001, 16(3):273-80.

36. The role of the pharmacist in self-care and self-medication in the prevention and treatment of diseases. Report of the 4th WHO Consultative Group on the role of the Pharmacist. Geneva, World Health Organization, 1998 (WHO/DAP/98.13).

37. Trap B, Lessing C. Zimbabwe: targets prescribing of opinion leaders. Essential drugs monitor, 1996, 21:4. 